\title{
Avaliação de bioensaios para a determinação da atividade biológica da gonadotrofina coriônica humana (hCG)
}

Claudia Maria BERTAN ${ }^{1}$

Pauline Martins da CUNHA ${ }^{1}$

Mario BINELLI ${ }^{1}$

José Antonio VISINTIN²

Mayra Elena Ortiz D'Avila

ASSUMPÇÃO ${ }^{2}$

Rubens Paes de ARRUDA ${ }^{1}$

Correspondência para:

CLAUDIAMARIA BERTAN

Centro de Biotecnologia em Reprodução Animal, Laboratório de Fisiologia e Endocrinologia Molecular da Faculdade de Medicina Veterinária e Zootecnia da Universidade de São Paulo, Av. Duque de

Caxias Norte, 225

13630-000 - Pirassununga-SP

binelli@usp.br

Recebido para publicação: 06/10/2003 Aprovado para publicação: 15/03/2005

\author{
1 - Departamento de Reprodução Animal da Faculdade de Medicina \\ Veterinária e Zootecnia da Universidade de São Paulo, Pirassununga - SP \\ 2 - Departamento de Reprodução Animal da Faculdade de Medicina \\ Veterinária e Zootecnia da Universidade de São Paulo, São Paulo - SP
}

\section{Resumo}

A atividade biológica de um hormônio é mensurada pela sua capacidade em exercer um determinado efeito biológico que possa ser quantificado. Os ensaios biológicos in vivo que avaliam a atividade do hCG baseiam-se na sua capacidade de promover um aumento de peso do sistema genital, vesículas seminais e próstata em ratos impúberes e útero e ovários em camundongas impúberes. A partir destes efeitos, determinam-se equações relacionando as doses de hCG administradas com o aumento de peso do sistema genital. O objetivo do presente estudo foi avaliar a eficiência de bioensaios em mensurarem a atividade biológica do hCG utilizando ratos, ratas e camundongas impúberes. No experimento 1 , ratos receberam $0,4,8$ ou $16 \mathrm{UI}$ de hCG, a cada 24 horas, durante 4 dias. A próstata e/ou as vesículas seminais foram pesadas 24 horas após a última injeção. No experimento 2, camundongas receberam $0,3,33,10,33,3$ ou $100 \mathrm{UI}$ de hCG, em um único dia. Os ovários e/ou útero foram pesados 24 horas após a última injeção. $\mathrm{O}$ hCG promoveu aumento de peso do sistema genital de camundongas, entretanto, não houve associação linear ou quadrática significativa entre as doses de hCG utilizadas e os pesos das variáveis medidas, impossibilitando a determinação de equações confiáveis. Os protocolos testados, com as doses de hCG utilizadas demonstraram eficiência e sensibilidade limitadas para a quantificação da atividade biológica do hCG.

\section{Introdução}

Integram a família dos hormônios glicoproteícos o hormônio luteinizante $(\mathrm{LH})$, hormônio folículo estimulante (FSH), hormônio tireo-estimulante (TSH) e a gonadotrofina coriônica humana (hCG). Segundo Pierce e Parsons ${ }^{1}$ todos os membros desta família são heterodímeros formados pela associação não covalente de uma subunidade $\alpha$, comum a todos estes hormônios, com uma subunidade $\beta$, que confere a especificidade aos diferentes hormônios da família.

O hCG é secretado pelas células trofoblásticas na mulher gestante e pode ser facilmente detectado na urina ${ }^{2}$, de onde normalmente é extraído e purificado para a elaboração de produtos comerciais. A atividade biológica de um hormônio é mensurada pela sua capacidade em exercer um determinado efeito biológico que possa ser quantificado. Para a mensuração da atividade biológica do hCG foram desenvolvidos alguns ensaios biológicos in vivo utilizando roedores impúberes $3,4,5,6,7,8,9,10$, 11. Tais ensaios são utilizados pela indústria farmacêutica para estimar a atividade biológica do hCG contido nos produtos comerciais. Estes ensaios baseiam-se na capacidade do hCG em promover o desenvolvimento e o aumento de peso do 
sistema genital em roedores impúberes.

Em ratos impúberes o hCG interage com os receptores do hormônio luteinizante (LH), localizados nas células de Leydig e atua estimulando a produção de AMP cíclico e a liberação de testosterona. A testosterona liga-se a receptores específicos presentes nas vesículas seminais e próstata. Nestes tecidos a testosterona determina uma ação biológica que resulta no desenvolvimento, aumento de tamanho e peso das glândulas anexas que compõem o sistema genital masculino, principalmente das vesículas seminais.

Em camundongas impúberes, a adenohipófise não libera pulsos de LH com freqüência e amplitude suficientes para estimular a síntese de progesterona, entretanto, receptores de LH são expressos nas células granulosas e tecais do ovário ${ }^{12}$. A administração de hCG em ratas e camundongas impúberes determina uma resposta biológica que inclui a indução da ovulação $^{13}$, hiperemia ovariana ${ }^{14,15}$, aumento de peso ovariano ${ }^{14}$ e aumento do peso uterino ${ }^{16}$. Hipkin $^{17}$ relata que a deidroepiandrosterona (DHA) estimula o crescimento e o aumento do peso do útero de ratas tratadas com hCG.

O princípio dos bioensaios baseia-se na relação do aumento de peso dos órgãos que compõem o sistema genital de animais impúberes com as diferentes doses de hCG administradas em unidades internacionais (UI), relação que possibilitaria a determinação de uma equação. A partir de tal equação, seria possível estimar a atividade biológica de hCG, em UI por quantidade de proteína, contida em amostras de atividade desconhecida. Este estudo teve como objetivo avaliar a eficiência de dois diferentes bioensaios realizados em condições experimentais semelhantes. A hipótese deste estudo é que o crescimento dos órgãos do sistema genital de ratos e camundongas impúberes tratadas com quantidades conhecidas de UI de hCG determina uma equação que caracteriza confiabilidade a estes bioensaios.

\section{Materiais e Métodos}

Os experimentos foram realizados na Universidade de São Paulo, na Faculdade de
Medicina Veterinária e Zootecnia, no Centro de Biotecnologia em Reprodução Animal, no Laboratório de Fisiologia e Endocrinologia Molecular.

\section{Experimento 1 - Ensaio biológico para mensurar a} atividade biológica do hCG em ratos impúberes.

Este experimento objetivou comparar o desenvolvimento das vesículas seminais e/ou próstata de ratos impúberes tratados com diferentes doses de hCG com ratos não tratados, segundo a técnica utilizada por Lugaro, Giannattasio e Casellato ${ }^{18}$; Hakola et al. ${ }^{19}$ e Diczfalusy e Loraine ${ }^{3}$.

\section{Delineamento Experimental.}

Foram utilizados 13 ratos (Ratus ratus) não púberes, com 27 dias de idade, linhagem "Wistar", provenientes do Biotério do Departamento de Patologia da Faculdade de Medicina Veterinária e Zootecnia da Universidade de São Paulo. Os ratos foram alojados em gaiolas recebendo água, ração balanceada e um fotoperíodo de 12 horas de luz/dia. Os ratos foram identificados na base da cauda, pesados individualmente e divididos eqüitativamente de acordo com o peso corporal em quatro grupos. A médias de peso vivo dos ratos foram de $68,1 \pm$ 3,$61 ; 69,3 \pm 0,88 ; 68,93 \pm 3,28$ e $68,86 \pm$ 3,24 gramas para os grupos $0,4,8$ e $16 \mathrm{UI}$, respectivamente. Os animais receberam 0 $(n=4), 4(n=3), 8(n=3)$ ou $16(n=3)$ UI de hCG (Pregnyl ${ }^{\circledR}$ 5000UI, NV Organon, Holanda), via intra-peritoneal, no volume de $0,5 \mathrm{~mL}$, uma vez ao dia, com um intervalo de 24 horas entre as aplicações, durante 4 dias consecutivos. Aproximadamente 24 horas após a última injeção os animais foram individualmente pesados e eutanasiados por inalação de éter sulfúrico. Foi realizada a abertura da cavidade abdominal e um exame macroscópico post mortem das vesículas seminais e próstata. Tais estruturas foram localizadas, isoladas, minuciosamente dissecadas, secadas em papel filtro e pesadas inicialmente em conjunto (vesículas seminais e próstata) e posteriormente isoladas. 
Análise Estatística.

A variável independente foi tratamento e a variável dependente peso das vesículas seminais e/ou próstata ajustadas para o peso vivo. Os dados foram testados quanto à normalidade dos resíduos e a homogeneidade das variâncias, premissas que foram respeitadas. Os dados foram analisados pela variância dos quadrados mínimos pelo modelo GLM do SAS ${ }^{20}$. Por análises de regressão linear e quadrática as médias dos tratamentos foram separadas por contrastes ortogonais ( 0 vs. 4, 8 e $16 \mathrm{UI}$; 4 vs. 8 e $16 \mathrm{UI} ; 8$ vs. $16 \mathrm{UI})$. Foi considerado um nível de significância de 5\%.

\section{EXPERIMENTO 2 - ENSAIO BIOLÓGICO PARA MENSURAR A ATIVIDADE BIOLÓGICA DO hCG EM CAMUNDONGAS IMPÚBERES}

Esse experimento objetivou comparar o desenvolvimento do sistema genital (útero e/ou ovários) de camundongas impúberes tratadas com diferentes doses de hCG com camundongas não tratadas, segundo a técnica utilizada por Nisula ${ }^{11}$.

\section{Delineamento Experimental.}

Foram utilizadas 30 camundongas (Mus musculus) não púberes, com 22 dias de idade, linhagem "Suiça", provenientes do Biotério Central da Universidade de São Paulo de

Tabela 1 - Contrastes Ortogonais referentes ao aumento de peso dos órgãos que constituem o sistema genital ajustado pelo peso vivo de ratos e camundongas impúberes tratados (as) com diferentes doses (UI) de Gonadotrofina Coriônica Humana (hCG)

\begin{tabular}{|c|c|c|c|}
\hline Experimento & Variáveis dependentes & trastes (UI de hCG) & $\operatorname{Pr}>\mathrm{F}$ \\
\hline $\begin{array}{l}\text { Experimento } \\
\qquad 1\end{array}$ & $\begin{array}{l}\text { Peso das Vesículas Seminais ajustadas } \mathrm{p} / \\
\text { peso vivo }\end{array}$ & $\begin{array}{l}\text { O vs. } 4,8 \text { e } 16 U \mathrm{I} \\
4 \text { vs. } 8 \text { e } 16 U l \\
8 \text { vs. } 16 U \mathrm{Ul}\end{array}$ & $\begin{array}{l}0,5042 \\
0,5439 \\
0,0829\end{array}$ \\
\hline $\begin{array}{l}\text { Ratos } \\
\text { Impúberes }\end{array}$ & $\begin{array}{c}\text { Peso das Vesículas Seminais e Próstata } \\
\text { ajustadas p/ peso vivo }\end{array}$ & $\begin{array}{l}\text { O vs. } 4,8 \text { e } 16 U \mathrm{I} \\
4 \text { vs. } 8 \text { e } 16 \mathrm{UI} \\
8 \text { vs. } 16 \mathrm{UI}\end{array}$ & $\begin{array}{l}0,1172 \\
0,1295 \\
0,0237\end{array}$ \\
\hline $\begin{array}{l}\text { Experimento } \\
\qquad 2\end{array}$ & $\begin{array}{l}\text { Peso dos Ovários ajustado p/ peso vivo } \\
\text { Peso do Útero ajustado p/ peso vivo }\end{array}$ & 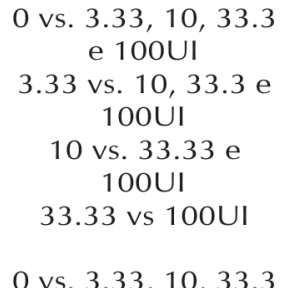 & $\begin{array}{l}0,0050 \\
0,9060 \\
0,4143 \\
0,0339 \\
0,0001 \\
0,3524 \\
0,5952 \\
0.2385\end{array}$ \\
\hline $\begin{array}{l}\text { Camundongas } \\
\text { Impúberes }\end{array}$ & $\begin{array}{c}\text { Peso dos Ovários e Útero ajustados p/ peso } \\
\text { vivo }\end{array}$ & 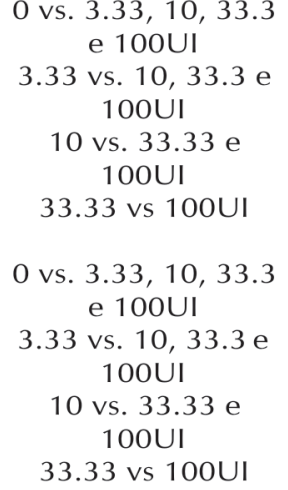 & $\begin{array}{l}0,2385 \\
0,0001 \\
0,3631 \\
0,3714 \\
0,0346\end{array}$ \\
\hline
\end{tabular}




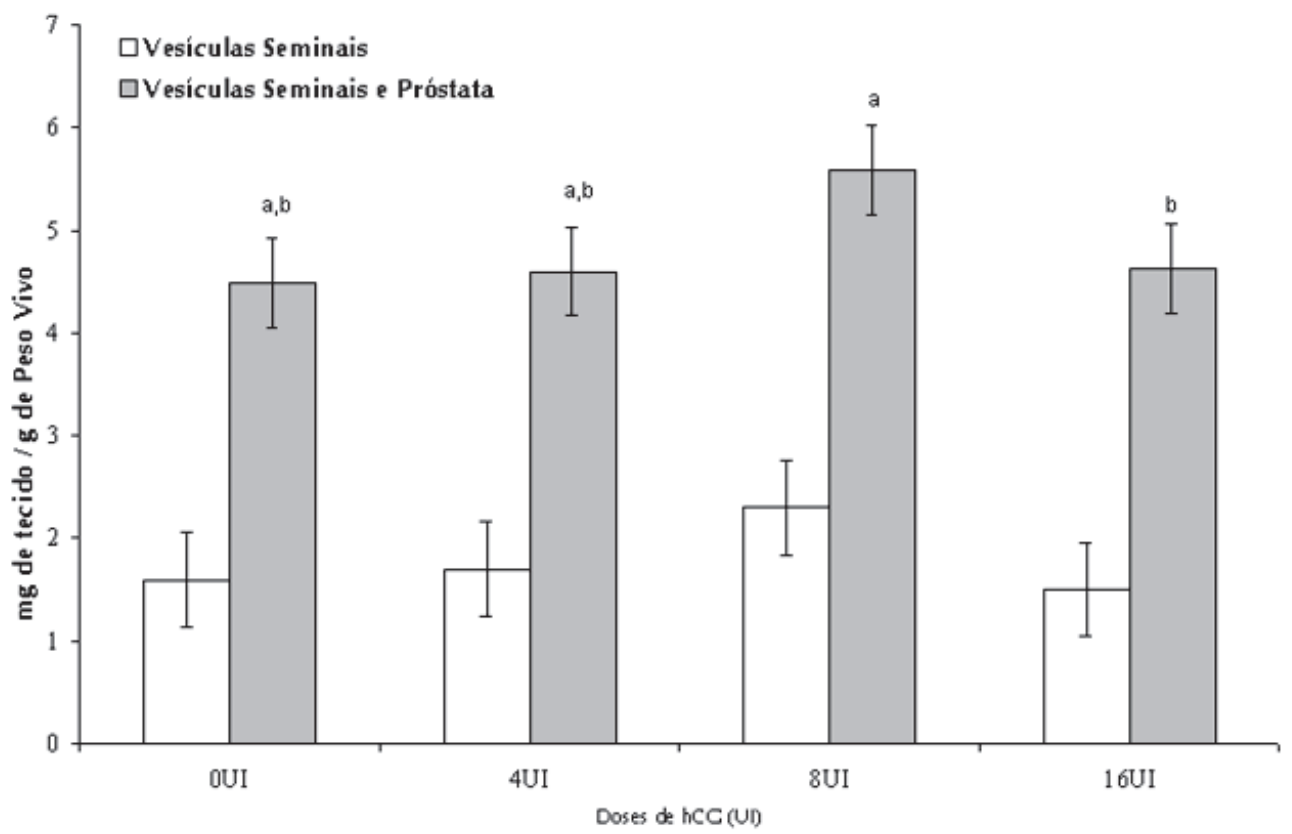

Figura 1 - Experimento 1 : Médias ( \pm desvios padrões) de peso das vesículas seminais e vesículas seminais/próstata ajustadas para o peso vivo em ratos impúberes tratados com diferentes doses de hCG $(\mathrm{UI})$ a,b Barras da mesma cor designadas por letras diferentes diferem significativamente $(\mathrm{P}<0,05)$

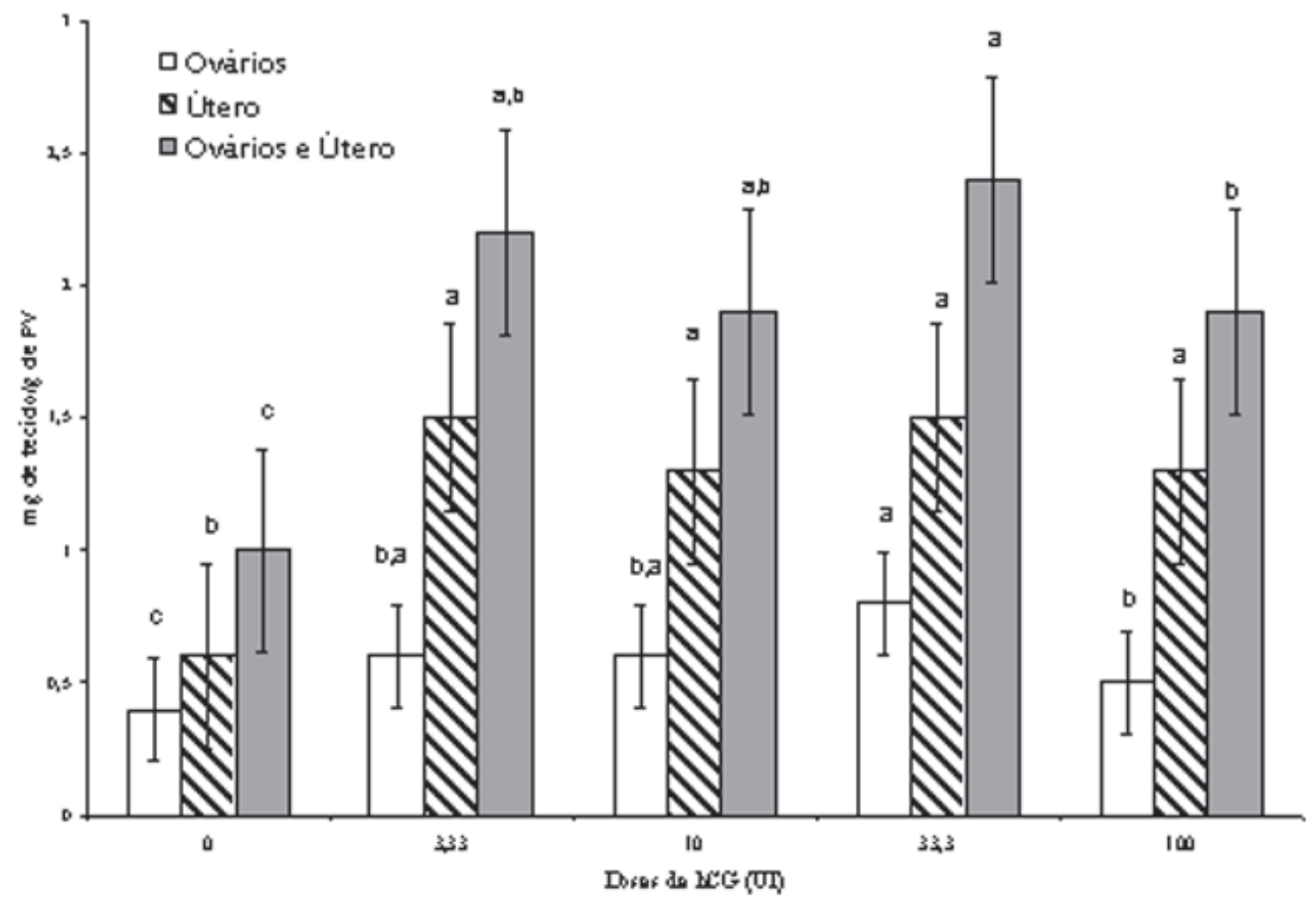

Figura 2 - Experimento 2: Médias ( \pm desvios padrões) de peso dos ovários, útero e ovários/útero ajustados para o peso vivo em camundongas impúberes tratadas com diferentes doses de $\mathrm{hCG}(\mathrm{UI}){ }^{\mathrm{a}, \mathrm{a}, \mathrm{c}}$ Barras da mesma cor designadas por letras diferentes diferem significativamente $(\mathrm{P}<0,05)$ 
Ribeirão Preto. As camundongas foram alojadas em gaiolas recebendo água, ração balanceada e um fotoperíodo de 12 horas de luz/dia. As camundongas foram identificados na base da cauda, pesadas individualmente e divididas eqüitativamente de acordo com o peso corporal em cinco grupos. A médias de peso vivo das camundongas foram de 16,94 $\pm 0,76 ; 16,95 \pm$ 0,$74 ; 16,94 \pm 0,67$ e $16,97 \pm 0,69$ gramas para os grupos $0 ; 3,33 ; 10 ; 33,3$ e 100UI, respectivamente. Os animais receberam $0(\mathrm{n}=6)$, 3,33 $(\mathrm{n}=6), 10(\mathrm{n}=6), 33,3(\mathrm{n}=6)$ ou $100(\mathrm{n}=6)$ UI de hCG (Pregny) ${ }^{\circledR}$ 5000UI, NV Organon, Holanda), via intra-peritoneal, no volume de $0,2 \mathrm{~mL}$, duas vezes ao dia, com um intervalo de 12 horas entre as aplicações, durante um dia. Aproximada-mente 24 horas após a última injeção as camundongas foram individualmente pesadas e eutanasiadas por inalação de éter sulfúrico. Foi realizada a abertura da cavidade abdominal e um exame macroscópico post mortem do útero e ovários. Tais estruturas foram minuciosamente dissecadas, secadas em papel filtro e pesadas inicialmente em conjunto e posteriormente isoladas.

\section{Análise Estatística.}

A variável independente foi tratamento e a variável dependente peso dos ovários, peso do útero e peso dos ovários e útero ajustados para o peso vivo. Os dados foram testados quanto à normalidade dos resíduos e a homogeneidade das variâncias, premissas que foram respeitadas. Os dados foram analisados pela variância dos quadrados mínimos pelo modelo GLM do SAS ${ }^{17}$. Por análises de regressão linear e quadrática as médias dos tratamentos foram separadas por contrastes ortogonais (0UI vs. 3,33, 10, 33,33 e 100UI; 3,33 vs. $10,33,33$ e $100 \mathrm{UI} ; 10 \mathrm{UI}$ vs. 33,33 e $100 \mathrm{UI}$; 33,33 UI vs. 100UI). Foi considerado um nível de significância de $5 \%$.

\section{Resultados e Discussão}

As médias de peso das vesículas seminais associadas ou não à próstata ajustadas pelo peso vivo dos animais estão representadas na Figura 1. A separação das médias por contrastes ortogonais estão apresentadas na tabela 1. No experimento 1 , não houve efeito de tratamentos para as médias de peso das vesículas seminais ajustadas para peso vivo. Foi observado efeito de tratamento na média de peso das vesículas seminais e próstata ajustadas pelo peso vivo dos ratos, onde a média do grupo tratado com 8UI de hCG foi maior $(\mathrm{P}<0,05)$ quando comparada a média dos animais tratados com 16UI. No presente experimento, verificou-se que as vesículas seminais de ratos com 31 dias de idade são extremamente finas, friáveis e pouco delimitadas anatomicamente. Estas particularidades dificultam a separação e dissecção das vesículas seminais do compartimento anatômico referente à próstata. Observou-se uma menor variação entre os animais quando as vesículas seminais e a próstata foram pesadas associadas. Nisula ${ }^{11}$ relatam que em ratos e camundongos impúberes, até então incapazes de produzir testosterona, o hCG estimula a produção de testosterona determinante para o desenvolvimento das glândulas anexas do sistema genital masculino, dentre essas as vesículas seminais e a próstata. Tal atividade biológica do hCG, no sistema genital de ratos impúberes, também foi observada por Lugaro, Giannattasio e Casellato ${ }^{18}$ e Hakola et al. ${ }^{19}$ No presente estudo, a ação do hCG em promover o aumento de peso das vesículas seminais e próstata não foi evidenciado. De fato, Diczfalusy e Loraine ${ }^{3}$ também não verificaram tal efeito do hCG em ratos impúberes. A relação do aumento de peso das vesículas seminais associadas à próstata ajustado para o peso vivo dos animais considerando as diferentes doses de hCG administradas, foi determinada por uma equação quadrática com um $\mathrm{R}^{2}$ de 0,26 .

Conforme ilustrado na tabela 1 e na figura 2, no experimento 2 houve efeito de tratamento no peso dos ovários ajustado para peso vivo $(\mathrm{P}<0,05)$. A média do grupo controle foi menor do que nos grupos tratados $(\mathrm{P}<0,05)$ e a média dos animais tratados com 33,3UI não diferiu dos tratados 
com 3,33UI e 10UUI, entretanto foi maior do que no grupo tratado com 100UI $(\mathrm{P}<0,05)$. Considerando o aumento de peso dos ovários ajustados pelo peso vivo das camundongas tratadas com $0,3,33,10$ e 33,3, onde se excluiu a dose de $100 \mathrm{UI}$, foi determinada por uma equação linear com um $\mathrm{R}^{2}$ de 0,3. Houve um efeito de tratamento no peso do útero sendo as médias dos grupos tratados maior $(\mathrm{P}<0,01)$ que a do grupo não tratado. $\mathrm{O}$ aumento de peso do útero ajustado pelo peso vivo das camundongas tratadas com 0, 3,33, 10 e 33,3UI foi determinada por uma equação quadrática com um $\mathrm{R}^{2}$ de 0,33 . Também houve efeito de tratamento no peso dos ovários/útero, sendo as médias dos grupos tratados maior $(\mathrm{P}<0,05)$ comparadas a média do grupo não tratado. No grupo tratado com 33,3UI o peso foi significativamente maior $(\mathrm{P}<0,05)$ que no tratado com 100UI $(\mathrm{P}<0,05)$, não tendo diferido dos grupos tratados com 3,33 e 10UI. Estes resultados confirmam que o hCG promove um aumento no peso do útero e ovários quando camundongas são tratadas com hCG. Entretanto, o aumento de peso do útero e ovários ajustado pelo peso vivo das camundongas tratadas com $0,3,33,10$ e 33,3 foi determinada por uma equação quadrática com um $\mathrm{R}^{2}$ de 0,22 . No presente experimento verificou-se que o isolamento e a dissecção do sistema genital das camundongas oferecem facilidade quando comparado ao isolamento das vesículas seminais e/ou próstata no experimento anterior com os ratos. Loraine e Lunn 8 trataram ratas impúberes com 6,25UI e 100UI de hCG e observaram um aumento significativo no peso do útero de animais tratados comparado aos não tratados, entretanto, o aumento de peso foi similar para os dois grupos tratados com hCG. Na literatura foram determinadas algumas curvas com o aumento do peso uterino utilizando 40 a 80 UI de $\mathrm{hCG}^{7}$ e 0,4 a 1,6UI de hCG ${ }^{17}$.

Nisula ${ }^{11}$ ilustra que os ensaios de bioatividade in vivo são pouco sensíveis comparados aos atualmente realizados in vitro, relatando que um cultivo de células da granulosa em presença de hCG estimularia a produção de progesterona que poderia ser mensurada no meio de cultivo, entretanto, esta técnica tem sido pouco empregada. Algumas técnicas de maior sensibilidade foram descritas nas quais foram utilizados cultivos de células de Leydig ${ }^{21,22,23}$. Nesta técnica, células de Leydig foram incubadas em um meio contendo diferentes doses de hCG e estimularam a produção de AMP cíclico e testosterona, que posteriormente foram mensuradas por radioimunoensaio. Segundo Nisula $^{13}$ neste método as concentrações de AMP cíclico e testosterona aumentam 45 minutos e 3 horas, respectivamente, após a administração de hCG ao meio de cultivo. No presente estudo o hCG promoveu aumento de peso do sistema genital de camundongas, entretanto, não houve uma associação linear ou quadrática significativa entre as doses de hCG utilizadas e os pesos das variáveis medidas, fato que impossibilita a determinação de equações confiáveis. Assim, conclui-se com o presente trabalho que os protocolos testados, com as doses de hCG utilizadas, demonstraram baixa confiabilidade para a quantificação da atividade biológica do hCG

\section{Evaluation of bioassays for measuring the of biological activity of Human Chorionic Gonadotropin (hCG)}

\section{Abstract}

Biological activity of a given hormone is measured by its capacity to exert a specific, quantifiable biological effect. Aim of biological assays that measure activity of hCG is to construct prediction equations that associate increasing doses of hCG with changes in weights of genitalia, seminal vesicles and prostate gland in pre-pubertal male rats and
Key words:

Bioassays

Human Chorionic

Gonadotropin.

Luteinizing Hormone.

Rats.

Mice. 
weights of uterus and ovaries in pre-pubertal female mice. Objective of the present study was to evaluate efficiency of bioassays which used pre-pubertal male rats and female rats and mice to measure hCG activity. In experiment 1 , male rats received $0,4,8$ or $16 \mathrm{IU}$ of hCG daily, for 4 days. Prostate and seminal vesicles were weighed 24 hours after last injection. In experiment 2 , female mice received $0,3.33,10$, 33.33 or $100 \mathrm{IU}$ of hCG in one day. Ovaries and uteri were weighed 24 hours after the last injection. The hCG increased weights of genitalia in female mice. However, there were no satisfactory linear or quadratic associations between doses of hCG used and variables measured. It was concluded that assays tested showed only limited efficiency and sensibility to quantify hCG biological activity.

\section{Referências}

1 PIERCE, J. G.; PARSONS, T. F. Glycoprotein hormones: structure and function. Annual Review of Biochemistry, v. 50, p. 465-495, 1981

2 BOUSFIELD, G. R.; PERRY, W. M.; WARD, D. N. Gonadotropins, chemistry and biosynthesis. In: KNOBIL, E.; NEILL, J. D. The Physiology of Reproduction. 2. ed. New York: Raven Press, 1994. Cap. 30.

3 DICZFALUSY, E.; LORAINE J. A. Journal of Clinical Endocrinology \& Metabolism, v. 15, p. 424, 1955.

04 TAJIC, M.; BACIC, M. The human chorionic gonadotrophin bioassay by seminal vesicles in mice. Experientia, v. 25, n. 3, p. 332-333, 1969.

05 ROBYN, C.; PETRUSZ, P.; DICZFALUSY, E. Follicle stimulating hormone-like activity in human chorionic gonadotrophin preparations. Acta Endocrinologica, v. 60, n. 1, p.137-156, 1969.

6 GIANNATTASIO, G.; LUGARO, G.; MANERA, E. Effects of the vehicle in the bioassay of human chorionic gonadotropin. Experientia, v.26, n. 11, p.1268, 1970.

7 JACOBS, M. M.; WARD, D. N.; GRIFFIN, A. C. A systematic analysis of the hCG augmentation assay for follicle stimulating hormone. Proceedings of the Society for Experimental Biology and Medicine, v. 144, n. 1, p.106-109, 1973.

8 LORAINE, J. A; LUNN S. F. The effect of initial body weigth on the response of the rat to treatment with gonadotrophins. Acta Endocrinologica, V.72, N.2, p. 218-225, 1973.

09 SHAEFER, J. M.; WEIDENFELD, J. The effects of HCG, indomethacin, flufenamic acid and aspirin in the immature female rat. Journal of Reproduction and Fertility, v. 45, n. 2, p. 227-33, 1975.

10 RIPPEL, R. H.; JONSON, E. S. Inhibition of HCG induced ovarian and uterine weight augmentation in the immature rat by analogs of $\mathrm{GnRH}$. Proceedings of the Society for Experimental Biology and Medicine, v. 152 , n. 3, p. 432-436, 1976
11 NISULA, B. C. Measurement of human chorion gonadotropin by biological methods. Scandinavian Journal of Clinical and Laboratory Investigation, V.53, p. 114-117, 1993.Supplement 216.

12 CAMP, T. A.; RAHAL, J. O.; MAYO, K E. Cellular localization and hormonal regulation on folliclestimulating hormone and luteinizing hormone receptor messanger RNAs in the rat ovary. Molecular Endocrinology, v.5, n.10, p. 1405-1417, 1991.

13 ZONDEK, B.; ASCHHEIM, S Hypophysenvorderlappenhormon und ovarium. Beziehungen der endokrinen Drusen zur Ovarial function. Arch Gynäk, v. 130, p. 1-45, 1927.

14 ZONDEK, B. Ueber die funktion des ovariums. Deutsch Medizine Wochenschrift, v. 8, p. 343-344, 1926.

15 ZONDEK, B.; SULMAN, F.;BLACK, R. The hyperemia effect of gonadotropins on the ovary. The Journal of the American Medical Association, v. 128, n. 13 , p. $939-944,1945$.

16 SIDDALL, A. C. A suggested test for pregnancy. The Journal of the American Medical Association, v. 90, p. 380, 1928.

17 HIPKIN, L. J. Modification of the rat uterine weight response to human chorionic gonadotrophin by oestrogen. Journal of Reproduction and Fertility, v. 34, n.1, p.175-7, 1973.

18 LUGARO, G.; GIANNATTASIO, G.; CASELLATO M. M. Influence of human serum on the determination of chorionic gonadotropin in impuberal rats. Folia Endocrinology, v. 21, n. 2, p. 243-252, 1968.

19 HAKOLA, K.; ET AL Recombinant rat luteinizing; production by Chinese hamster ovary cells, purification and functional characterization. Molecular and Cellular Endocrinology, V..128, N.1-2, p. 47-56, 1997.

20 SAS. SAS/STAT TM user's guide ( Release 6.03 ). Cary, NC: SAS Institute, 1988.

21 DUFAU, M. L.; MENDELSON, C. R.; CATT, K J. A highly sensitive in vitro bioassay for luteinizing hormone and chorionic gonadotropin: testosterone production 
by dispersed leydig cells. Journal of Clinical Endocrinology \& Metabolism, v. 39, n.3, p. 610-613, 1974.

22 JANSZEN, F .H. A.; COOKE, B. A.; VAN DRIEL, M. J. A; VAN DER MOLEN, H. J. Purification and characterization of leydig cells from rat testes. Journal Endocrinology, V. 70,N.3, p. 345-359, 1976.

23 MANNAERTS, B. M. J. L.; KLOOSTERBOER, H. J.; SCHUURS, A. H. W. M. Applications of in vitro bioassays for gonadotrophins. Neuro-endocrinology of Reproduction. Amsterdam: Elsevier Science, 1987, P.49-58 